\title{
Postnatal Care within One Week and Associated Factors among Women Who Gave Birth in Ameya District, Oromia Regional State, Ethiopia, 2018: Cross Sectional Study
}

\author{
Teshome Melesse Belihu ${ }^{1 *}$, Ababe Tamirat Deressa ${ }^{2}$
}

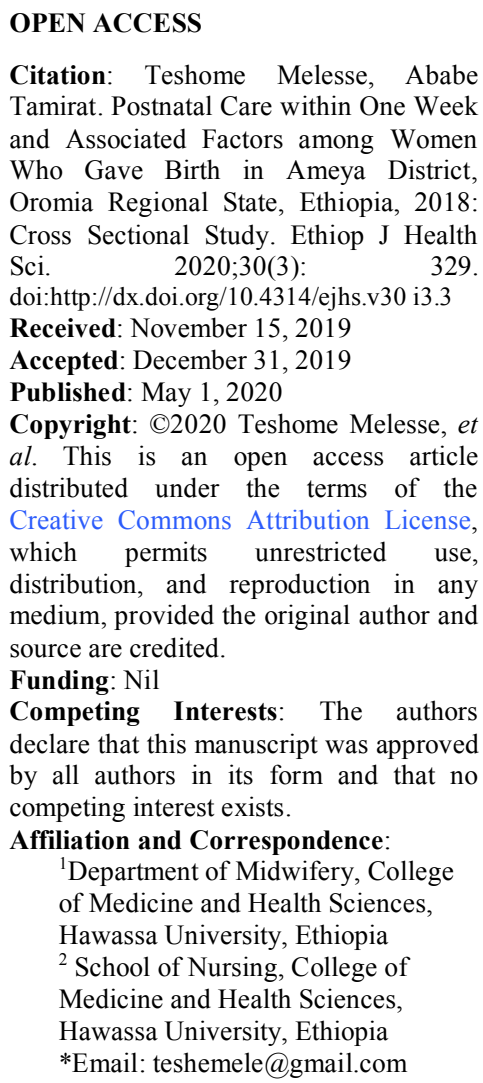

\begin{abstract}
BACKGROUND: Globally recorded large number of maternal and neonatal deaths are related to complications during pregnancy, childbirth and post-partum. Most neonatal deaths occur during the first week of life. It is also evidenced that the level of postnatal care utilization in Ethiopia is very low. This study aimed to assess postnatal care utilization within one week and associated factors among women who had given birth in the last six weeks in Ameya district, Oromia, Ethiopia.

METHODS: Cross sectional study design was employed on 332 study participants who were selected by systemic sampling method and interviewed using structured questionnaires. The data were analyzed using SPSS version 23.0. Bivariate and multivariate logistic regression analysis was used to identify the associated factors with the outcome variable. Figures, tables and sentences were used for the presentation of descriptive statistics.
\end{abstract}

RESULT: The finding revealed that the proportion of postnatal care utilization within one-week in the study area is 25.3\%. Partner occupation [AOR $=5.575,95 \% C I=(1.071,29.023)]$, mothers who had complication during labor and delivery $[A O R=7.841,95 \% C I=$ (2.287, 26.879)], distance from mothers to health facilities[AOR= $5.127,95 \% C I=(1.149,22.878)]$ and awareness on postnatal care within one week services[AOR=4.161, 95\% $C I=(1.300,13.314)]$ were the main contributing factors of postnatal care utilization within one-week.

CONCLUSION: Postnatal care utilization within one-week is very low (25.3\%). Partner occupation, complication during labor and delivery, distance from health facilities and awareness on postnatal care within one week service were the associated factors.

KEYWORDS: Postnatal care utilization, mothers, Oromia region

\section{INTRODUCTION}

Postpartum is the time when physiological changes that can affect future life of both mother and newborn takes place (1). Though it is most neglected, essential services like counseling on obstetrics and neonatal danger signs are given during post-natal period $(1,2)$. The World Health Organization (WHO) recommends the mother to get immediate postnatal care within the first 24 hours, 
2-3 days, 6-7 days and 6 weeks of delivery (1).

Globally, annual 289000 maternal and 2.9 million neonatal deaths was recorded. Large proportion of maternal death occurs at home in the first week of postnatal period regardless of place of delivery and delivery attendant. The death mostly occurred during labour, delivery, and the immediate postpartum period. Obstetric hemorrhage is the main medical cause of maternal death. Postnatal death within few days and hours of delivery accounts for $67 \%$ of this maternal death. $(1,3,4)$.

In Ethiopia, maternal mortality rate was high and large number of deaths occurred during postnatal period in the first week of delivery (5). On top of this, the level of any postnatal care utilization in this country was very low. As it is reported in Mini Ethiopia Demographic Health Survey (MEDHS), only 14\% women had received postnatal care services (6).

In Oromia region and Addis Ababa City administration, Ethiopia, only $9 \%$ and $55.4 \%$ of mothers who gave birth had sought postnatal care within two days respectively (7). History of having antenatal care and institutional delivery increased the probability of seeking postnatal care within one week of delivery (4).

Ethiopia is one of the countries following universal health coverage as strategy to decrease maternal and child mortality. This is believed to be achieved through capacitating health care providers, making accessible health facilities, increasing number of health extension workers (HEWs) and mobilizing the community $(8,9)$. However, still significant maternal death and disabilities are being recorded. Although utilization of postnatal care (PNC) within a week after delivery plays a crucial role to achieve the universal health coverage by having a healthy mother and newborn, it was neglected across the country (10). Thus, enhancing the service of antenatal care, delivery at health facilities, developing strategies to provide postnatal care at home and upgrading mothers' awareness were considered to increase the utilization of PNC services (4).

In Ameya district, Oromia regional state, Ethiopia, PNC utilization within one week after delivery is unknown. Hence, this study aimed to assess the PNC utilization within one week and associated factors in the district that can be a good baseline information to design strategies to increase the service utilization.

\section{METHODS AND MATERIALS}

Study area, design and period: Institutional based cross sectional study was conducted in Ameya district, South West Shewa, Oromia regional State, Ethiopia. Ameya district is situated at the South West of the country which is far from capital city of Ethiopia, Addis Ababa, about $144 \mathrm{~km}$. The district has 36 kebeles and two municipal towns, Gindo and Kota.

According to 2007 national census, the total population for the woreda is 122,056 , of whom 61,578 were males and 60,478 were females; 6,257 or $5.13 \%$ of its population were urban dwellers. The majority of the inhabitants are Ethiopian Orthodox Christianity (55.4\%), while $26.33 \%$ of the population were Protestant, and $17.66 \%$ were Muslim.

Medical and obstetrics care was provided by different health posts per kebele, health centers and private clinics. There are 8 health centers, 36 health posts and 3 private clinics in the district. In the district, there are 28 health extension workers and 63 healthcare providers (Health officers, Midwives, Nurses, Laboratorists and druggists). The study was conducted from February 15 March 15, 2018.

Source of population: All postnatal mothers who had given birth six weeks before actual data collection in Ameya district were source population.

Study population: Mothers who gave birth before six weeks were excluded to minimize risk of recall bias. A total of 332 selected mothers with systematic sampling based on the order of their flow among mothers who came for maternal and child health $(\mathrm{MCH})$ services to the selected health centers during study period were the study population.

Sample size determination: The prevalence of postnatal care utilization within one week in the country was unknown. Thus, by using $50 \%$ for the proportion of postnatal care utilization within one week, 95\% Confidence level, 5\% marginal error,

DOI: http://dx.doi.org/10.4314/ejhs.v30i3.3 
and applying single population proportion formula with correction formula, the final sample size was 302.

Sampling method: From Eight health centers, four of them were selected by simple random sampling method (lottery method) and proportional allocation of the size to each health center was performed depending on client's fellow. Participants were selected by using systematic sampling method for all respective selected health centers from the clients' order of flow. According to this procedure, the study unit was selected from every three (3) clients.

\section{Data collection instruments and} questionnaire development: Structured interviewer administered questionnaire was used to collect data. Questionnaire was adopted from different literatures and modified for the objective of the study. The Questionnaire contains sociodemographic characteristics, reproductive and obstetrics factors, knowledge on postnatal care within one week services of the mothers and health facilities related factors. All questions were prepared in English and translated into local language, Afan Oromo, and back translated into English by independent experts to maintain its consistency.

Data collection procedure: Data collectors were trained on the objectives of the study and techniques of interviewing the participants. Four diploma holder midwives were deployed as data collectors on each selected health center. Data collection was conducted through face-to-face interview using adopted and modified questionnaire. Every day, supervisors followed the activities of data collectors and the investigator guided the overall activities.

Quality assurance and management: Adopted and modified structured questionnaire was translated by fluent people in the local language (Afan Oromo). Then, again it was back translated into English by another independent expert to keep its consistency. Both the data collectors and supervisors were trained for two days on the objective and methodology of the research and data collection approach. Pre-test was undertaken on $5 \%$ of the participants two weeks before the actual data collection on one of the health centers (Hudad
2 Health Center) which had not been selected for the main study to modify if any ambiguity on the questionnaire. Before starting data collection, data collector had taken written or verbal consent from participants. Privacy and confidentiality of the participant were ensured. Once interview was finished, data collectors checked all questionnaires for completeness before the respondent left. Lastly, all questionnaires were checked for its completion by the supervisor every day

Data processing and analysis: After data was collected, filled questionnaires were coded and checked for completeness, consistency and clarity. Data was entered into EpiData 3.5 and exported to SPSS version 23.0 software for analysis. Frequency tables and descriptive summaries were used to describe the study variables. Bivariate and multivariate logistic regression analysis were performed to produce crude and adjusted odds ratio. Variables that had P-value $<0.2$ in bivariate analysis were entered into multivariate logistic regression and finally, $\mathrm{P}$-values $<0.05$ were considered to declare significant statistical association.

Ethical consideration: Ethical clearance and official letter were obtained from Addis Ababa University Research and Ethics Committee Department of Nursing and Midwifery. After getting permission from the district office, request letter was sent to the respective health centers' managers. The health center managers informed $\mathrm{MCH}$ and the record unit of health facilities. Informed written and verbal consent were secured from each study participant. Finally, participants' privacy and confidentiality was ensured throughout the time of data collection.

\section{RESULTS}

Socio-demographic characteristics: A total of 332 postpartum mothers participated in the study; the response rate was $100 \%$. From all participants, about 168(50.6\%) belonged to the age group of 2535 with mean age of 27.82 (SD of \pm 5.88 ). One hundred ninety-two $(62.1 \%)$ and one hundred twenty-one $(39.2 \%)$ of the women's partners were farmers and had no formal education, respectively (Table 1). 
Obstetrics complications and reproductive characters of mothers: The majority $(82.8 \%)$ of the mothers had no history of abortion. Two hundred sixty $(78.3 \%)$ and $64(19.3 \%)$ had given less than four births. A large proportion,
290(87.3\%), had ANC follow-up. Of all mothers who had developed complication after delivery, more than half $(54 \%)$ sought care from health institution immediately (Table 2).

Table 1: Socio demographic characteristics of mothers in the district

\begin{tabular}{|c|c|c|}
\hline Variables & Frequency & Percent \\
\hline \multicolumn{3}{|l|}{ Age in years } \\
\hline$<25$ & 126 & 38.0 \\
\hline $25-35$ & 168 & 50.6 \\
\hline$>35$ & 38 & 11.4 \\
\hline \multicolumn{3}{|l|}{ Religion } \\
\hline Orthodox & 162 & 48.8 \\
\hline Muslim & 79 & 23.8 \\
\hline Protestant & 91 & 27.4 \\
\hline \multicolumn{3}{|l|}{ Ethnicity } \\
\hline Oromo & 269 & 81.0 \\
\hline Amara & 60 & 18.1 \\
\hline Gurage & 3 & 0.9 \\
\hline \multicolumn{3}{|l|}{ Place of residence } \\
\hline Urban & 138 & 41.6 \\
\hline Rural & 194 & 58.4 \\
\hline \multicolumn{3}{|l|}{ Current marital status } \\
\hline Married legally/with friend & 309 & 93.1 \\
\hline Unmarried & 23 & 6.9 \\
\hline \multicolumn{3}{|l|}{ Maternal level of education } \\
\hline No formal education & 173 & 52.1 \\
\hline primary education & 98 & 29.5 \\
\hline High school education & 40 & 12.0 \\
\hline Above high school education & 21 & 6.3 \\
\hline \multicolumn{3}{|c|}{ Partner level of Education $(n=309)$} \\
\hline No formal education & 121 & 39.2 \\
\hline primary education & 109 & 35.3 \\
\hline High school education & 45 & 14.6 \\
\hline Above high school education & 34 & 11.0 \\
\hline \multicolumn{3}{|l|}{ Occupation of mother } \\
\hline Employer & 24 & 7.2 \\
\hline Merchant & 49 & 14.8 \\
\hline Daily laborer & 8 & 2.4 \\
\hline House wife & 251 & 75.6 \\
\hline \multicolumn{3}{|l|}{ Husband occupation $(n=309)$} \\
\hline Farmer & 192 & 62.1 \\
\hline Employer & 38 & 12.3 \\
\hline Merchant & 62 & 20.1 \\
\hline Daily laborer & 17 & 5.5 \\
\hline
\end{tabular}

DOI: http://dx.doi.org/10.4314/ejhs.v30i3.3 
Table 2: Obstetrics complication of the mothers in the last pregnancy, delivery and postpartum period

\begin{tabular}{lll}
\hline \multicolumn{1}{c}{ Variables } & Frequency & Percent \\
\hline Complication faced during pregnancy & 60 & 18.1 \\
Yes & 272 & 82.9 \\
No & & \\
Complications faced at time of delivery & 54 & 16.3 \\
Yes & 278 & 83.7 \\
No & & 63.0 \\
Type of complications at time of delivery $(\mathbf{n}=\mathbf{5 4})$ & 34 & 27.8 \\
Prolonged labor & 15 & 9.3 \\
Fetal distress & 3 & 19.0 \\
PIH (Preeclampsia/Eclampsia) & & 81.0 \\
Complications faced after delivery & 63 & \\
Yes & 269 & 93.8 \\
No & & 6.3 \\
Ehe reason why surgery was performed for the mother $(\mathbf{n}=\mathbf{1 6})$ & 15 \\
Elective surgery & 1 & \\
\hline
\end{tabular}

Mode of delivery of the mothers in the district: The majority of respondents, 275(82.8\%), delivered spontaneously via vaginal delivery. Forty one $(12.3 \%)$ and sixteen $(4.8 \%)$ delivered by instrumental delivery and obstetrics caesarian section $(\mathrm{C} / \mathrm{S})$, respectively.

Health facilities and health care providers' factors: From 332 participants, 248 mothers gave birth at health facilities. Out of those who gave birth at health facilities, 29(17.8\%) had been given postnatal care appointments within 2-7 days of delivery. Almost all, 160(98.2\%), of the mothers were appointed for postnatal care at six weeks of delivery.

Even if a large proportion of deliveries were attended by health professionals, the majority of the mothers had not been advised on maternal and neonatal postpartum complications. The result showed that a few proportion of the mothers $(15.4 \%)$ had been visited at their home after delivery mostly by health extension workers (HEWs).

Prevalence of postnatal care within one-week utilization: From the total respondents, about $84(25.3 \%)$ had utilized PNC within one week of postpartum after discharge from health facilities
Awareness and barriers to utilization of PNC within one week: Only $72(21.7 \%)$ of the mothers had awareness of PNC within one week and the reported pertinent factor to inhibit mothers from seeking PNC within one week service was cultural influence (Table 3).

Factors associated with PNC within one-week utilization: Mothers whose husband were employee were 6 times more likely to utilize PNC within one week of delivery as compared to those whose husbands were farmer [AOR $=5.575,95 \%$ $\mathrm{CI}=(1.071,29.023)]$. Mothers who had complications during labor and delivery were almost 8 times more likely to utilize PNC within one week of delivery than those who had no complication during labor and delivery $[\mathrm{AOR}=7.841,95 \% \quad \mathrm{CI}=(2.287,26.879)] . \quad$ In addition, mothers living near to health facility had more odds of utilizing PNC within one week of delivery compared to those who were far from health center $[\mathrm{AOR}=5.127,95 \% \mathrm{CI}=(1.149$, 22.878)]. Also, mothers who had awareness of PNC within one week services were 4 times more likely to utilize PNC within one week of delivery compared to those who had no awareness $[\mathrm{AOR}=4.161,95 \% \mathrm{CI}=(1.300,13.314)]$ (Table 4).

DOI: http://dx.doi.org/10.4314/ejhs.v30i3.3 
Table 3: Awareness of mother and postnatal care within one week utilization

\begin{tabular}{lll}
\hline Variables & Frequency & Percent \\
\hline Awareness of mothers on PNC one week services & 72 & 21.7 \\
Yes & 260 & 78.3 \\
No & & \\
Specific awareness mothers had & 57 & 79.2 \\
Physical examination & 37 & 51.4 \\
Physical examination for new born, & 30 & 41.7 \\
Family planning service, & 36 & 50.0 \\
Immunization services, & 34 & 47.2 \\
Advising on postpartum complications, & 26 & 36.1 \\
Advising on nutrition & 27 & 37.5 \\
Breast feeding practice & & \\
Barriers to utilized one week PNC (n= 248) & 101 & 40.6 \\
Culture & 4 & 1.6 \\
Waiting for falling off of baby's cord stump & 62 & 24.9 \\
To have enough energy & 13 & 5.2 \\
Lack of time & 5 & 2.0 \\
Lack of guardians for my children & 3 & 1.2 \\
Waiting the service kill the time & 22 & 8.9 \\
Lack information of advice & 13 & 5.2 \\
Health professionals were not care client in good manner
\end{tabular}

Table 4: Factors associated with postnatal care utilization within one week

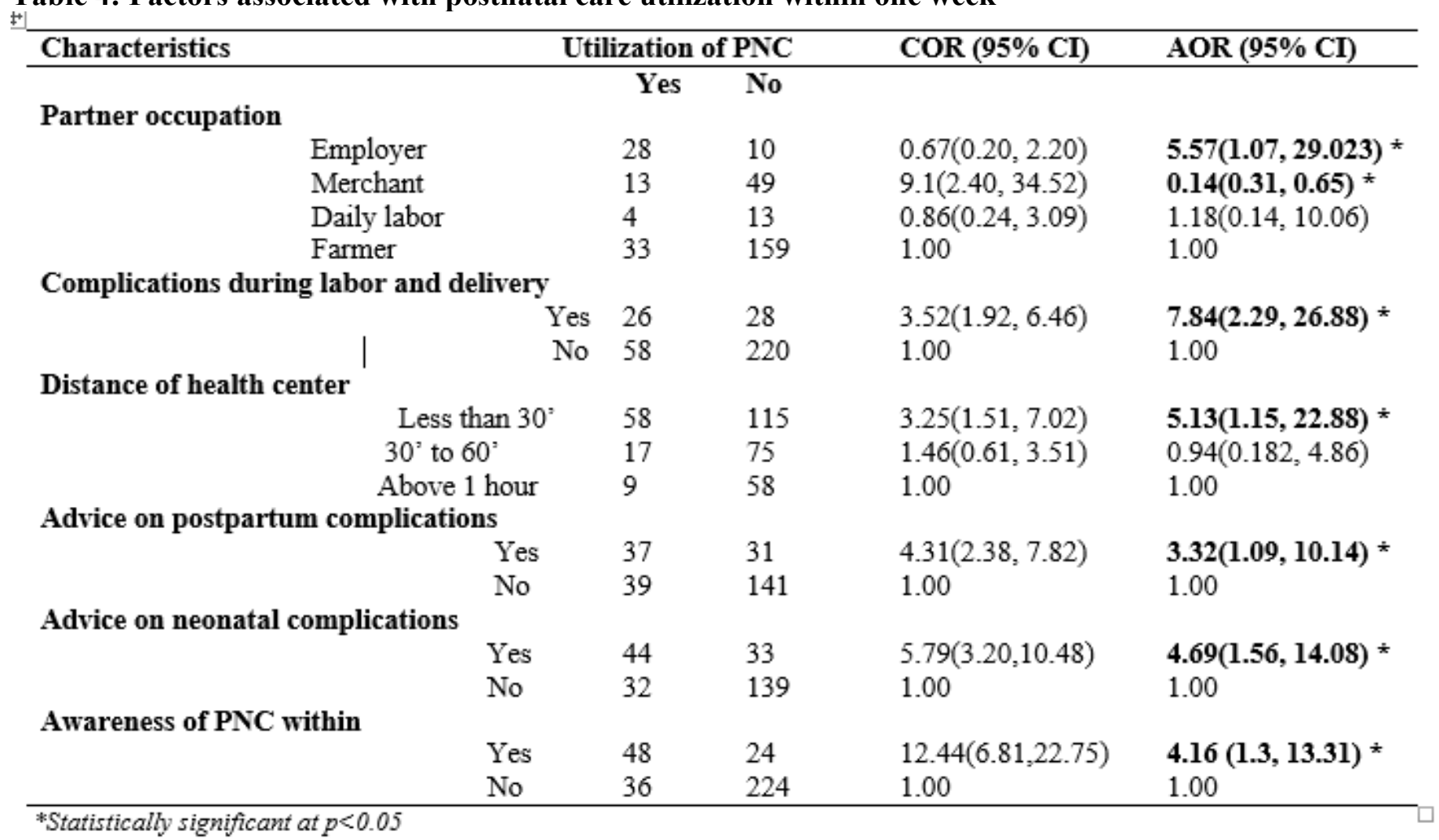

DOI: http://dx.doi.org/10.4314/ejhs.v30i3.3 


\section{DISCUSSION}

The study verified that postnatal care utilization within one week was $25.3 \%$ in the district. This is almost comparable with a study conducted in Burkina Faso which was 25\% (5) and a research conducted in Jabitena, Ethiopia, which was $20.2 \%$ (11). The small variation with research conducted in Jabitena, Ethiopia, may be due to the time difference that could be improvement in accessing and utilizing healthcare service through time. On the other hand, the prevalence of utilization of postnatal care within one week in this study was significantly higher than the previous report of EDHS which was $9 \%$ for PNC within the first two days of delivery (12) and lower than reports from Kenya, Malawi and Mozambique in 2015 (5). The difference might be due to study time variation for that of EDHS, and study design, study population and study area for the other studies.

Also, this prevalence was higher than study conducted in India, M. Pradesh, in 2014 which was $4.3 \%$ (13) and the research undergone in China in 2014 which was 8\% (14). This may be due to methodological and study time variation.

Partner occupation in this study was found to have statistically significant association with PNC utilization within one week of delivery. The mothers whose husbands were employees had highly utilized the service than those whose husbands were farmers. This may be due to the fact that occupation of husbands directly influence their socio-economy which affects the lifestyle of the family. However, mothers whose husbands were merchant were less likely to utilize PNC within one week than mothers whose husbands are government employee. The possible reason might be due to being busy of those husbands who are merchants; they may be unable to accompany the mother when she wants to visit health facility. Maternal occupation, educational level and place of delivery were significantly associated with postnatal care utilization in different countries and Abi Adi, Tigrai, Ethiopia (15), but in this study these were not significantly associated. This may be due to geographical and methodology variation.

Another factor affecting PNC utilization within one week was having complication during labor and delivery. Mothers who had developed complication during labor and delivery more utilized the service when compared to those who had not developed any complication. This was consistent with the studies conducted in Nepal in 2011 and in Nigeria in $2014(16,17)$. This may be probably due to the fact that the mothers who had complication at time of delivery were consulted by health providers immediately after delivery and advised on the necessity of PNC within one week utilization.

Distance from health center had also a significant statistical association with utilization of PNC within one week of delivery. Mothers who lived nearby health facility and walk less than 30 minutes to reach health facility were more likely to utilize PNC when compared to mothers who lived far from health facility. This was similar to the result showed in studies conducted in Tanzania in Hebei, China and Kenya (14, 18, and 19).

Mothers who had awareness about PNC within one week services in this study more utilized PNC within one week than those who did not have awareness about PNC within one week service and this is similar with study conducted in Tanzania in 2009 (19).

\section{ACKNOWLEDGEMENT}

First, we express our gratitude to Addis Ababa University (AAU) for its academic support. Next, we would like to thank the participants and Ameya health office for their cooperation. Also, our heartfelt thank goes to our friend, Abdulsemad Bahiru, for psychological and material support to do this study.

\section{REFERENCES}

1. World Health Organization. WHO recommendations on postnatal care of the mother and newborn. World Health Organization; 2014.

2. Berhe H, Tilahun W, Aregay A, Bruh G, Gebremedhim H. Utilisation and associated factors of postnatal care in Adwa Town, Tigray, Ethiopia - a cross sectional study.

DOI: http://dx.doi.org/10.4314/ejhs.v30i3.3 
Advanced Research in Pharmaceuticals and Biologicals. 2013;3(1):353-9.

3. Singh A, Padmadas SS, Mishra US, Pallikadavath S, Johnson FA, Matthews Z. Socio-economic inequalities in the use of postnatal care in India. PloS one. 2012;7(5):e37037.

4. Sines E, Syed U, Wall S, Worley H. Postnatal care: A critical opportunity to save mothers and newborns. 2007.

5. Duysburgh E, Kerstens B, Kouanda S, Kaboré $\mathrm{CP}$, Yugbare DB, Gichangi $\mathrm{P}$, et al. Opportunities to improve postpartum care for mothers and infants: design of context-specific packages of postpartum interventions in rural districts in four sub-Saharan African countries. $B M C$ pregnancy and childbirth. 2015; 15(1):131.

6. Agency CS. Ethiopia mini demographic and health survey 2014. Central Statistical Agency Addis Ababa, Ethiopia, 2014.

7. CSA, ICF Demographic, and ICF Ethiopia . Health Survey 2016: key Indicators Report. Addis Ababa, Ethiopia, and Rockville, Maryland, USA: 2016.

8. Organization WH. Making fair choices on the path to universal health coverage: final report of the WHO Consultative Group on Equity and Universal Health Coverage. 2014.

9. Alebachew A, Hatt L, Kukla M. Monitoring and evaluating progress towards Universal Health Coverage in Ethiopia. PLoS medicine. 2014;11(9):e1001696.

10. Worku AG, Yalew AW, Afework MF. Factors affecting utilization of skilled maternal care in Northwest Ethiopia: a multilevel analysis. $B M C$ international health and human rights. 2013;13(1):20.

11. Workineh YG, Hailu DA. Factors affecting utilization of postnatal care service in Jabitena district, Amhara region, Ethiopia. Sci J Public Health. 2014;23:169-76.
12. CSA, ICF Demographic, and ICF Ethiopia. Health Survey 2016: key Indicators Report. Addis Ababa, Ethiopia, and Rockville,Maryland, USA. 2016.

13. Sharma A, Thakur PS, Kasar PK, Tiwari R, Sharma R. Utilization of post natal care in tribal area of Madhya Pradesh: a community based cross sectional study. Age (in years). 2014;15:24.

14. Chen L, Qiong W, van Velthoven $\mathrm{MH}$, Yanfeng Z, Shuyi Z, Ye L, et al. Coverage, quality of and barriers to postnatal care in rural Hebei, China: a mixed method study. BMC Pregnancy and Childbirth. 2014;14(1):31.

15. Alemayeh H, Assefa H, Adama Y. Prevalence and factors associated with post natal care utilization in Abi-Adi town, Tigray, Ethiopia: A cross sectional study. IJPBSF International Journal of Pharmaceutical and Biological Sciences Fundamentals. 2014;8(01):23-35.

16. Khanal V, Adhikari M, Karkee R, Gavidia T. Factors associated with the utilisation of postnatal care services among the mothers of Nepal: analysis of Nepal demographic and health survey 2011. BMC women's health. 2014;14(1):19.

17. Oluwaseyi SD. Determinants of postnatal care non-utilization among women in Nigeria. Johannesburg: University of Witwatersrand; 2014.

18. Kinuthia MPM. Factors affecting utilization of postnatal care services in Kenya. South American Journal of Public Health. 2014;2(3).

19. Mrisho M, Obrist B, Schellenberg JA, Haws RA, Mushi AK, Mshinda H, et al. The use of antenatal and postnatal care: perspectives and experiences of women and health care providers in rural southern Tanzania. $B M C$ pregnancy and childbirth. 2009; 9(1):10. 